\title{
Lithium Overdose with Electrocardiogram Changes Suggesting Ischemia
}

\author{
Joshua Puhr, MD, Jason B. Hack, MD, Jacquelyn A. Early, MD, William L. Price, MD, \\ William J. Meggs, MD, PhD
}

Department of Emergency Medicine, Brody School of Medicine at East Carolina University, Greenville, North Carolina

\begin{abstract} vation myocardial infarction have not been reported.

\section{INTRODUCTION}

Lithium overdoses are associated with variable electrocardiographic changes including QT prolongation, ST segment changes, and $\mathrm{T}$ wave changes [1-3]. Cardiac arrhythmias of junctional bradycardia, sinus node dysfunction, ventricular systolic, and asystole have been reported [4-6]. Rarely, myocardial infarction has been reported [7]. We report an unusual case of transient ST segment elevations suggesting an acute myocardial infarction in a patient with a chronic lithium overdose and altered mental status on presentation.
\end{abstract}

Background: Lithium toxicity is associated with electrocardiogram (ECG) changes, but changes suggestive of an ST segment ele-

Case Report: A 46-year-old incarcerated man suffering from diabetes, hypertension, and schizoaffective/bipolar disorder was treated with lithium 1,200 mg twice daily. Two days prior to presentation the patient became confused, ataxic, and anorexic in jail. Lithium level was $4.69 \mathrm{mmol} / \mathrm{L}$. He was transferred to the emergency department. On arrival, vital signs were normal. The ECG showed a normal sinus rhythm. ST segments were elevated in the anterior leads with downward concavity. T waves were biphasic. Since these changes suggested cardiac ischemia and the patient was unable to respond to questions about chest pain, cardiac enzymes and an emergent echocardiogram were done. Troponin I was less than $0.1 \mu \mathrm{g} / \mathrm{L}$. Echocardiogram was normal, without wall motion abnormalities. Treatment was with hemodialysis and whole-bowel irrigation. Postdialysis lithium level was $1.30 \mathrm{mmol} / \mathrm{L}$. Over the next several days, electrocardiogram normalized. His speech gradually became coherent. After a 1-week hospitalization, he returned to jail.

Conclusion: Lithium intoxication can cause transient ST segment elevations suggesting an acute myocardial infarction. In the absence of a clear history, echocardiogram and cardiac enzymes can be used to rule out a myocardial infarction.

\section{CASE REPORT}

A 46-year-old incarcerated man suffering from diabetes, hypertension, and schizoaffective/bipolar disorder was treated with lithium 1,200 mg twice daily. Other medications administered to him were glipizide, metformin, haloperidol, aspirin, quetiapine, benztropine, losartan, haloperidol, and pantoprazole. Two days prior to presentation the patient became confused, ataxic, and anorexic in jail. His lithium level was $4.69 \mathrm{mmol} / \mathrm{L}$. He was transferred to the emergency department (ED). On arrival, his vital signs were normal. He was awake but confused, with jerking movements of the extremities. His speech was incoherent. Laboratory profile revealed BUN of 25 with an otherwise normal basic metabolic panel, WBC count of $14,000 / \mathrm{mm}^{3}$ without bands, and lithium level of $4.61 \mathrm{mmol} / \mathrm{L}$. Electrocardiogram (ECG) showed a normal sinus rhythm. ST segments were elevated in the anterior leads with downward concavity. T waves were biphasic. More specifically, V1 with $1 \mathrm{~mm}$ of ST segment elevation, V2 with $2 \mathrm{~mm}$ of ST segment elevation, and V3 with $1.5 \mathrm{~mm}$ of ST segment elevation (Figure 1). These changes were not

Keywords: lithium, poisoning, electrocardiogram abnormalities, cardiac toxicity There was no outside funding of any kind used for this study. Corresponding Author: William J. Meggs, MD, PhD, Department of Emergency Medicine, Brody School of Medicine at East Carolina University, Greenville, NC 27858. Email: meggsw@ecu.edu 


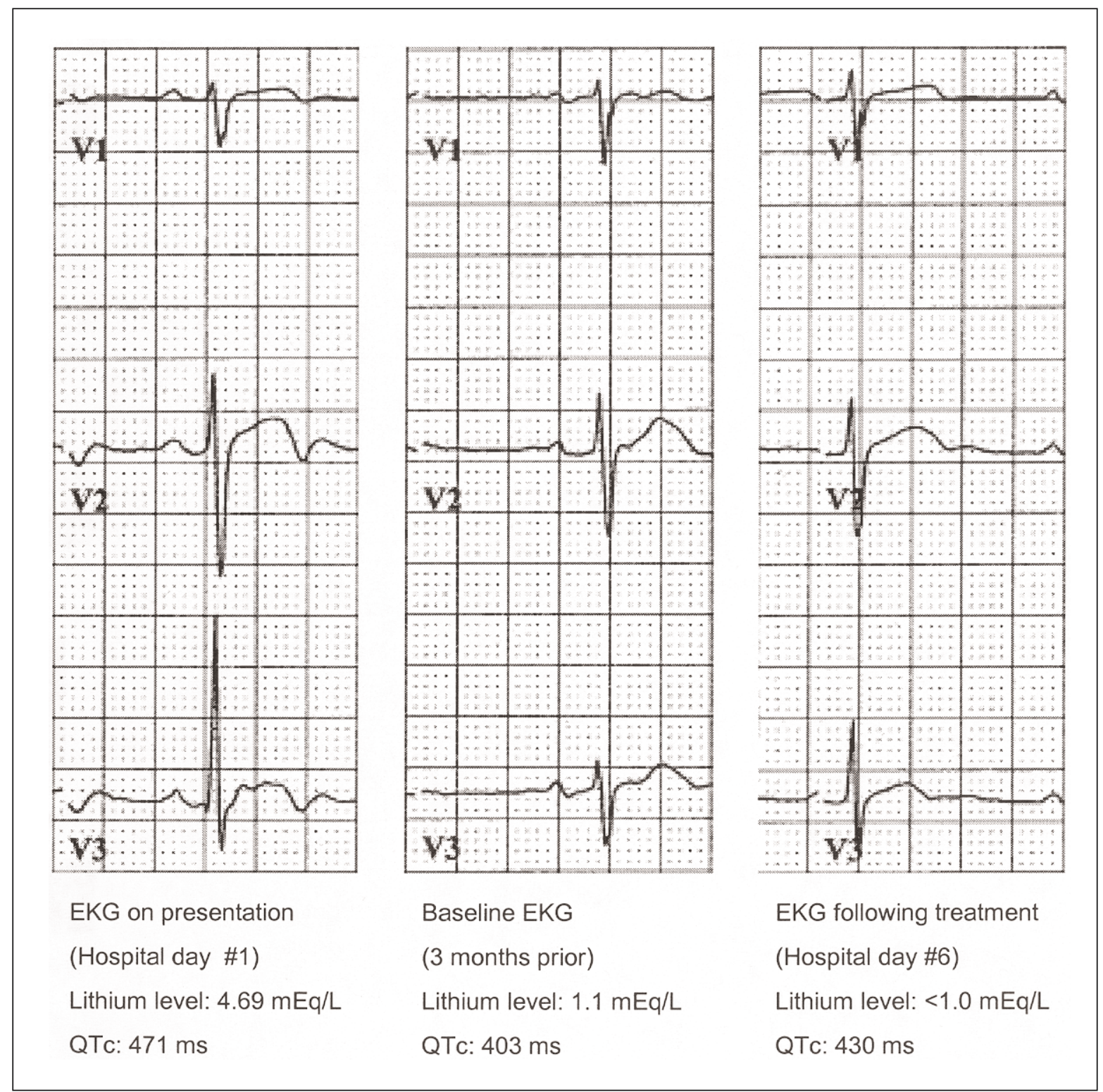

Figure 1: ECG changes suggesting acute myocardial infarction in a patient with a lithium overdose, compared with an ECG performed 3 months before and immediately after the poisoning.

present on an ECG performed 3 months earlier. Since these changes suggested cardiac ischemia and the patient was unable to respond to questions about chest pain, cardiac enzymes and an urgent echocardiogram were done. Troponin I was less than $0.1 \mu \mathrm{g} / \mathrm{L}$. The echocardiogram was normal, without wall motion abnormalities. He was treated with hemodialysis and whole-bowel irrigation. Dialysis was continued until his lithium level fell below $2.0 \mathrm{mmol} / \mathrm{L}$. His postdialysis lithium level was $1.05 \mathrm{mmol} / \mathrm{L}$, and his lithium levels were checked every 3 hours after dialysis to monitor for rebound. Lithium rose to $1.57 \mathrm{mmol} / \mathrm{L}$ at 3 hours after dialysis ended, then fell to $0.64 \mathrm{mmol} / \mathrm{L} 3$ hours later without further dialysis. Total time on the hemodialysis machine was 6 hours.
Over the next several days, his ECG normalized. His speech gradually became coherent. After a 1-week hospitalization, he returned to jail. At the time of discharge from the hospital, he was oriented to person and place but not to time, and was mildly confused. No follow-up was available after discharge.

\section{DISCUSSION}

This patient's altered mental status precluded the ED staff from obtaining a clear history of chest pain. With an ECG suggesting an acute myocardial infarction, cardiac enzymes and an emergency echocardiogram were used to rule out myocardial infarction. 
Resolution of electrocardiac abnormalities with extracorporeal elimination of lithium suggested that ECG changes associated with lithium toxicity can be misinterpreted as cardiac ischemia.

Lithium causes toxicity through several mechanisms including competition with sodium, potassium, calcium, and magnesium ions, which play important roles in cellular membrane physiology. This effect is what causes the ECG changes such as QT prolongation and nonspecific ST segment and T wave abnormalities. ECG changes are more likely to occur with chronic lithium overdoses than acute overdoses [8]. Although the patient ruled out for myocardial infarction, our findings cautiously suggest that lithium toxicity may mimic an anatomical injury pattern on ECG. A literature search did not find any previous case reports of lithium toxicity associated with ST segment elevation.

This patient was treated with both hemodialysis and wholebowel irrigation for what may have been a case of chronic toxicity, though it was impossible to determine if this was a chronic or acute-on-chronic ingestion. The efficacy of hemodialysis for chronic lithium intoxications has been questioned because intracellular lithium diffuses slowly from cellular compartments [9] and rebound can occur [10]. Minimal rebound was seen in this case, perhaps because there was an acute element to this ingestion.

Whole-bowel irrigation is often recommended for acute lithium ingestions and has been demonstrated to reduce serum lithium concentrations in a volunteer study [11]. The value of whole-bowel irrigation in chronic overdoses has not been demonstrated and is unlikely to be beneficial because it is unlikely that significant amounts of lithium remain in the gastrointestinal track. In the absence of definitive evidence that the overdose in this case was not an acute or acute-on-chronic overdose, wholebowel irrigation was performed.

In this case electrocardiographic changes were seen 2 days after the onset of neurological toxicity. Cardiac toxicity has been described as lagging neurological toxicity by that time period [12]. In the case reported here, an ECG was not performed until 2 days after the onset of toxicity, so it is not possible to date when electrocardiographic changes occurred.

\section{CONCLUSION}

Electrocardiographic changes associated with lithium toxicity can mimic cardiac ischemia, which can be ruled out with a bedside echocardiogram showing the absence of wall motion abnormalities and cardiac enzymes.

The authors have no potential financial conflicts of interest to report.

\section{REFERENCES}

1. Hsu CH, Liu PY, Chen JH, Yeh TL, Tsai HY, Lin LJ. Electrocardiographic abnormalities as predictors for over-range lithium levels. Cardiology 2005;103:101-106.

2. Jacob AI, Hope RR. Prolongation of the Q-T interval in lithium toxicity. J Electrocardiol 1979;12:117-119.

3. Tilkian AS, Schroeder JS, Kao JJ. Cardiovascular effects of lithium in man: A review of the literature. Am J Med 1976; 61:665-670.

4. Farag S, Watson RD, Honeybourne D. Symptomatic junctional bradycardia due to lithium intoxication in patient with previously normal electrocardiogram. Lancet 1994;343:1371.

5. Rosenqvist M, Bergfeldt L, Aili H, Mathe AA. Sinus node dysfunction during long-term lithium treatment. Br Heart $J$ 1993;70:371-375.

6. Ong AC, Handler CE. Sinus arrest and asystole due to severe lithium intoxication. Int J Cardiol 1991;30:364-366.

7. Perrier A, Martin PY, Favre H, Muller AF, Urban P, Chevrolet JC. Very severe self-poisoning lithium carbonate intoxication causing a myocardial infarction. Chest 1991;100:863-865.

8. Linakis J, Woolf A. Clinical features of acute versus chronic lithium overdose. Vet Human Toxicol 1989;31:370.

9. Okusa MD, Crystal LJ. Clinical manifestations and management of acute lithium intoxication. Am J Med 1994;97:383-389.

10. Bosanaki T, Baile GR, Eisele G. Massive and extended rebound of serum lithium concentrations following hemodialysis in two chronic overdose cases. Am J Emerg Med 1998;16:98-100.

11. Smith SW, Ling LJ. Whole bowel irrigation as a treatment for acute lithium overdose. Ann Emerg Med 1991;20:536-539.

12. Waring WS. Delayed cardiotoxicity in chronic lithium poisoning: discrepancy between serum lithium concentrations and clinical status. Basic Clin Pharmacol Toxicol 2007; 100:353-355. 